\title{
Unexplained hemolytic anemia of pregnancy: Case report with review of related literature
}

\author{
Paban Sharma, Rekha Sthapit \\ Gyne/Obst Department, Patan Hospital, Nepal
}

\begin{abstract}
We present a case of a multipara lady who developed hemolytic anemia during pregnancy with spontaneous remission after delivery. She was managed with low dose steroid for hemolysis during pregnancy with good feto-maternal outcome. Despite extensive investigations carried out to determine the cause, they remained in vain. Very few of such cases have been described in the literature, which merits its presentation.
\end{abstract}

Key words: Hemolytic anemia, pregnancy

\section{Introduction}

Pregnancy associated hemolytic anemia is a very rare condition with unexplained entity. With extensive search in English literature, we could retrieve only 21 such cases. The disease can manifest in both first and second trimester with a high incidence of fetal loss. We report such a case of hemolytic anemia associated with pregnancy with repeated fetal losses and given birth to two babies when treated with steroid.

\section{Case}

A 30 yrs lady with a history of laparotomy for ectopic pregnancy outside, presented in our hospital 8 yrs back (2057 BS) with the history of generalized swelling of the body for last 15 days and no fetal movement for one day. At that time she was at 31 weeks of gestation and having no proper antenatal check up. She was treated for jaundice at 10 weeks of gestation in other hospital in Kathmandu with no improvement despite repeated blood transfusion and extensive investigations. On physical examination she was pale, puffy and icteric. Her blood pressure was elevated (170/ $100 \mathrm{~mm} \mathrm{Hg} \mathrm{Rt,} \mathrm{150/90} \mathrm{mm} \mathrm{Hg} \mathrm{Lt).} \mathrm{She} \mathrm{had} \mathrm{a} \mathrm{gravid}$ uterus of around 28 weeks size and fetal heart sound was present at that time. Besides this there were no other clinically significant findings.

Her hemoglobin was low with high reticulocyte count. Peripheral smear shows microcytic normochromic picture and leukocyte and the platelet count were normal. Serum bilirubin was slightly elevated with the presence of urinary bilinogen. She was investigated for the possibility of sickle cell disease and hemoglonopathies but the reports were normal. Test for syphilis was also non reactive and assay for G6PD deficiency was also negative. Ante-nuclear antibody and test for malaria parasite also came to be negative. Bone marrow report shows hypercellular with erythroid hyperplasia. $24 \mathrm{hrs}$ urinary protein was $284 \mathrm{mg} / \mathrm{dl}$ and she had normal serum creatinine. Her blood group was A positive.

A working diagnosis of hemolytic anemia of pregnancy with the possibility of preeclampsia/HELLP was made and antihypertensive medicine was started along with other supportive management and blood transfusion. Next day ultrasound report shows intrauterine fetal death of 29 weeks fetus with maternal ascites and pleural effusion. Predniosolone $60 \mathrm{mg}$ daily started for ongoing hemolysis. Subsequently after being stable a 
induction was done which resulted into a macerated still birth female baby of $1250 \mathrm{gm}$.

Following delivery, hypertension was well controlled and hematocrit started to rise. She was discharged on $10^{\text {th }}$ day of admission. Steroid was tapered on subsequent visit in OPD. Later on low dose steroid was restarted thinking of possibility of autoimmune hemolysis because she developed oral ulcer and spleen tip was palpable with some features of hemolysis.

15 months later, she conceived again while she was on low dose steroid. Doses of steroid was readjusted according to the level of hematocrit and reticulocyte count and stopped at 37 weeks. Pregnancy was uneventful this time. She delivered a healthy female baby of 2750 gram at 38 weeks. On $45^{\text {th }}$ day of postpartum visit she developed papules on the body and reticulocyte count was high at that time, so low dose steroid was restarted. During $8^{\text {th }}$ post-partum months steroid was stopped and she lost follow up.

After 4 years, she conceived again but did not continue beyond 12 weeks, had spontaneous complete miscarriage. Again, after 4 months she conceived and again landed into spontaneous complete miscarriage at 8 weeks. She was not on steroid during these periods. After 9 months, she conceived again. Test for antiphospolipid syndrome was done and it was negative. In view of previous history, steroid was again restarted at 23 weeks, continued till term and baby delivered by caesarean section at 38 weeks for failed induction. Steroid tapered and stopped in subsequent follow up. She has no problem now after 1 year post delivery and having no features of hemolysis.

\section{Comment}

Hemolytic anemia associated with pregnancy is a rare condition and very few such cases have been described in literature. A similar case was reported in the year of 2001, in which early trimester pregnancy was associated with hemolysis, remission occurred after delivery and there was recurrence in subsequent pregnancies. There was no causal factor despite of extensive investigations. There was no response to steroid and even to intravenous immunoglobin. So, patient was managed with blood transfusion only. ${ }^{1}$
Goodall et. al reported a similar case of hemolytic anemia induced by pregnancy in otherwise healthy women with negative family history. ${ }^{2}$ Starksen NF et al published 19 cases of unexplained hemolytic anemia in pregnancy in 1983. In their series, $38 \%$ of anemia started in first trimester and similar percentage of anemia started in second trimester. Hemolysis resolved within 5 months following delivery in $95 \%$ situation and there were recurrence of hemolysis in $50 \%$ cases in subsequent pregnancies. They also found a transient hemolysis in four of 19 (22\%) infants ${ }^{3}$. In our case we did not observe hemolysis in both new born. The etiology of this problem is unknown, and the only factor clearly associated with the anemia is the gravid state. Characteristic of this problem is the absence of any identifiable immune mechanism or intracorpuscular or extracorpuscular defects despite the use of specific and sensitive complement-fixation antibody consumption techniques and assay of all red blood cell enzymes. ${ }^{3}$ Although there is no consensus in the management, steroid may be helpful to prevent hemolysis if they respond to it. Repeated transfusions may be necessary to prevent severe anemia and its consequences. They can have a normal delivery.

\section{Conclusion}

Pregnancy associated hemolytic anemia is a very rare situation with unknown etiology. The only associated factor is known to be is the presence of gravid state. The paucity of such cases merits its presentation.

\section{References}

1. Kumar R, Advani AR, Sharan J, Basharutallah MS, Al-Lumai AS. Pregnancy induced hemolytic anemia: an unexplained entity. Ann Hematol 2001 Oct; 80(10):623-6.

2. Goodall BC, Ho-Yan Do, Clarh DM, Thomson MA, Browning MC, Crowder AM. Hemolytic anemia of pregnancy. Scand J Haematol (1979); 22:185-191.

3. Starksen NF, Bell WR, Kickler TS. Unexplained hemolytic anemia associated with pregnancy. Am J Obstet Gynecol 1983 Jul 15;146(6):617-22. 